\title{
On the presence of Brachytrupes megacephalus Lefebvre 1827 (Orthoptera, Gryllidae) in the Natural Reserve "Simeto Oasis" (Sicily, Italy)
}

\author{
Alfredo Petralia $¥$, Pietro Fiandaca§, Ettore Petralia ${ }^{\ddagger}$, Giorgio Sabella§, Gaetano Torrisil, Corrado \\ Bianca ${ }^{\ddagger}$, Francesco Lamanna \\ $\ddagger$ Association "Ente Fauna Siciliana", Noto, Italy \\ $\S$ Department of Biological Geological Environmental Sciences, University of Catania, Catania, Italy \\ | Administration of the Metropolitan City of Catania, Catania, Italy \\ If Association "Chloe", Strongoli, Italy
}

Corresponding author: Alfredo Petralia (alfredo.petralia@yahoo.it)

Received: 13 Sep 2019 | Published: 13 Sep 2019

Citation: Petralia A, Fiandaca P, Petralia E, Sabella G, Torrisi G, Bianca C, Lamanna F (2019) On the presence of Brachytrupes megacephalus Lefebvre 1827 (Orthoptera, Gryllidae) in the Natural Reserve "Simeto Oasis" (Sicily, Italy). ARPHA Conference Abstracts 2: e46538. https://doi.org/10.3897/aca.2.e46538

\begin{abstract}
The authors present the first results of a survey on the presence of Brachytrupes megacephalus (Orthoptera species described by Alexandre Lefebvre in 1827 from specimens found in Sicily) in the Natural Reserve (NR) "Simeto Oasis". The NR is located along the Sicilian Ionian sandy coast just south of the city of Catania, at the mouth of the most important in river Sicily, Simeto.

Brachytrupes megacephalus is a south Mediterranean species living in the sandy environments of Sicily, Aeolian Islands, Maltese islands, south Sardinia, North Africa. Due to its rarity in Europe, the species was included in Annexes II and IV of the European Directive $92 / 43$ as one that requires special protection.

This cricket is vegetarian, hygrophilous, yellowish in color, normally crepuscular and nocturnal. It is a burrowing animal living in tunnels that the individuals dig by the expulsion of the excavated sand by means of a very spectacular behavioural pattern involving its forelegs and the large head; this activity produces typical small irregular sandy cones on
\end{abstract}


the ground surface, which reveals the presence of the animals (Conti et al. 2012). By detecting these formations, and also the entrances of the tunnels, it is possible to map the presence of $B$. megacephalus (Petralia et al. 2015).

The species was present in the NR and was well represented in all the areas in which the soil has not been altered by the diverse human activities. The very intensive anthropization of the NR (e.g. houses, roads, cultivations, trampling, pollution, artificial changes of the vegetation) has subtracted vital space for the species; however, up to now the specie has survived even under difficult conditions and has been able to re-colonize the areas where the anthropic disturbance had ceased.

The purpose of this research is to provide the management authority of the NR with useful information for the planning of appropriate safeguard measures aimed at limiting the anthropic pressure as well as measures aimed at protecting and restoring the habitat of the species, a fundamental condition for its survival.

\section{Keywords}

Orthoptera, sandy environments, species mapping, natural reserve

\section{Presenting author}

Alfredo Petralia

\section{Presented at}

$\mathrm{V}^{\text {th }}$ International Congress on Biodiversity: „Taxonomy, Speciation and Euro-Mediterranean Biodiversity“

\section{References}

- $\quad$ Conti E, Costa G, Petralia A, Petralia E (2012) Eco-ethology of Brachytrupes megacephalu s (Orthoptera, Gryllidae), protected species in EU. Atti e Memorie dell'Ente Fauna Siciliana Vol. XI: 51-56. [In English].

- $\quad$ Petralia A, Petralia E, Sabella G, Brogna F, Bianca C (2015) Presence's mapping of Brachytrupes megacephalus (Lefebrve, 1827)(Orthoptera, Gryllidae) within the Natural Reserve of Vendicari. Biodiversity Journal 6: 323-326. [In English]. 